\title{
Asynchronous Online Discussions During Case-Based Learning: A Problem-Solving Process
}

\author{
Adrie A. Koehler, Holly Fiock, and Shamila Janakiraman \\ Purdue University \\ Zui Cheng \\ Southern University of Science and Technology \\ Huanhuan Wang \\ Smart Learning Institute of Beijing Normal University
}

\begin{abstract}
Asynchronous discussions are typically considered an essential aspect of online case-based learning. While instructors implement discussions to support a variety of instructional purposes during case-based learning (e.g., facilitate students' sense making, prompt the consideration of diverse perspectives, debate complex topics), whether students receive the expected benefits is unclear, and little research has considered how students intentionally participate in discussions to support their learning during case-based learning. At the same time, students' participation in asynchronous online discussions represents a complex endeavor. That is, students must make several decisions regarding how to effectively participate, while simultaneously experiencing several challenges. The purpose of this exploratory multiple-case study was to consider the experiences of six graduate students participating in asynchronous online discussions as a part of a case-based course. By analyzing these experiences, we were able to conceptualize students' navigation of an asynchronous online discussion as a problem-solving process and consider individual problem-solving approaches. Results indicate that students relied primarily on instructors to determine the purpose of their discussion participation, expressed differing levels of value for participating in discussions, adopted a variety of strategies to meet discussion participation goals, and assessed their participation efforts mainly based on guidelines set by the instructor. We offer suggestions for effectively designing and facilitating asynchronous online discussions and discuss areas needing future research.
\end{abstract}

Keywords: asynchronous online discussions, case-based learning, problem solving

Koehler, A.A., Cheng, Z., Fiock, H., Janakiraman, S., \& Wang, H. (2020). Asynchronous online discussions during case-based learning: A problem-solving process. Online Learning, 24(4), 64-92. https://doi.org/10.24059/olj.v24i4.2332 


\section{Asynchronous Online Discussions During Case-Based Learning: A Problem-Solving Process}

Problem-centered methods, such as case-based learning, are difficult for learners, as they must direct their own learning (Ge \& Land, 2003). Compared to face-to-face settings, these challenges have the potential to be intensified in online settings, where learners share more ownership in the learning process (Galustyan et al., 2019; Moore, 2013; Tainsh, 2016). Asynchronous online discussions offer learners a medium for making sense of complex problems present in cases and monitoring their problem-solving efforts during case-based learning (Putnam et al., 2012; Rovai \& Jordan, 2004; Wu et al., 2013). However, effective asynchronous online discussions are only as strong as the contributions of the participants (Ertmer \& Koehler, 2015), and to gain the most from an asynchronous online discussion, participants must be intentional about how they approach and navigate a discussion (Wu et al., 2013). If learners are not intentional with their discussion participation, then, the potential for the discussion to support personal problem solving is limited. In short, as learners are participating in problem-centered methods, they are simultaneously completing a problem-solving process as they participate in asynchronous online discussions. That is, learners must determine how to effectively approach and navigate an asynchronous discussion to best support their learning.

Little research has considered how learners use discussions to monitor and support their understanding during problem-centered methods. In this research, we examined the experiences of six graduate students as they navigated asynchronous online discussions as part of a case-based course. From reviewing these experiences, we were able to create six problem-solving paths that students adopted during case-based discussions. After conceptualizing each student's approach, we considered the effectiveness of approaches and offered suggestions for case-based discussion facilitation and research.

\section{Review of Relevant Literature}

\section{Case-Based Learning}

As an instructional approach, case-based learning is a process centered on real-world, illstructured stories with multiple and often ambiguous solutions. Case-based learning offers learners opportunities to gain experience with connecting and applying concepts vicariously in a low-stakes environment (Ertmer \& Koehler, 2014; Jonassen \& Hernandez-Serrano, 2002). Across diverse domains, researchers have explored case-based learning extensively (Choi \& Lee, 2009; Ertmer \& Koehler, 2014, 2015, 2018; Tawfik, 2017), finding that it can be an effective instructional method for developing problem-solving skills (Koehler et al., 2019; Tawfik \& Jonassen, 2013; Tawfik \& Kolodner, 2016).

Learners can gain several benefits from completing the case-based learning process. First, case-based learning offers learners the opportunity to consider problems similar to ones they will encounter in professional settings and make connections between these problems and the learners'

existing knowledge (Hofsten et al., 2010; Schwartz et al., 1994). Additionally, case-based learning can develop learners' "teamwork, critical thinking, and cultural awareness" skills (Yadav et al., 2015, p. 1554). Finally, research suggests that case studies are positively correlated with students' motivation (Yadav et al., 2007). 
The case-based learning process comprises several elements: cases focused on problems of practice, the completion of case analyses (Ertmer \& Koehler, 2014), collaborative discussions (Ertmer \& Koehler, 2015), and reflection on the entire process (Tawfik \& Kolodner, 2016). While case-based learning can be meaningful for learners, the process may be overwhelming for them as they manage complex topics to make sense of stakeholders' perspectives and integrate previous knowledge and experiences with case content (Choi \& Lee, 2009; Mostert, 2007). In online settings, asynchronous discussions are central to an effective learning experience. Some research indicates that when structured appropriately, instructors can use discussions to scaffold learners' experience (Ertmer \& Koehler, 2015; Goeze et al., 2014, Koehler et al., 2019).

\section{Asynchronous Online Discussions}

Across distance and adult learning theories, a common expectation is that learners share responsibility in shaping their learning and navigating the online learning experience (Galustyan et al., 2019; Moore, 2013; Tainsh, 2016). A primary way that learners take ownership in online courses is through their navigation of asynchronous online discussions, as they provide a medium for learners to interact with peers and instructors through writing, reading, and responding to posts related to course content and experiences while brainstorming solutions to problems (Hew et al., 2010; Putnam et al., 2012; Ringler et al., 2015). Asynchronous online discussions offer learners a medium to examine perceptions, consider new ideas, and facilitate social and collaborative processing while building a sense of community (Garrison et al., 2001). As a result of the asynchronous nature of this type of communication, learners can reflect on questions and revisit posts in a flexible manner in order to build critical thinking and problem-solving skills (Cheung \& Hew, 2004; Garrison et al., 2001; Putnam et al., 2012; Rovai \& Jordan, 2004; Wu et al., 2013).

As asynchronous online discussions provide opportunities for instructors to facilitate knowledge construction, collaborative learning, cognitive engagement, and socializing among learners (Weltzer-Ward, 2011; Xie \& Huang, 2014; Zhu, 2006), they align well with case-based learning, as a key aspect of the process is centered on considering and reflecting on diverse perspectives of peers (Ertmer \& Koehler, 2014). Specifically, in case-based learning, asynchronous online discussions enable learners to explore complex problems, analyze possible causes of the problems, and generate solutions addressing identified problems (Anderson et al., 2008; Wu et al., 2013). For instance, in a case-based asynchronous online discussion where students analyzed and interpreted data in order to solve complex real-world science problems, Missett et al. (2010) found that learners were engaged and improved their learning.

Overall, in case-based learning, discussions offer learners a space to externalize ideas, elicit feedback, and work through differences in opinion while completing the problem-solving process (Tawfik et al., 2017). In short, they offer learners a medium to monitor (e.g., learners' awareness of their understanding and performance when completing specific learning tasks, [Schraw et al., 2002]) their problem-solving during case-based learning and provide opportunities for learners to gain internal feedback about their performance on specific learning tasks (Winne, 1996). As a result, learners can control their cognitive process, and the more accurate learners' monitoring is, the more able they are to regulate the learning process (Baars, 2014)..

\section{Asynchronous Online Discussion Participation: An Ill-Structured Problem-Solving Process}

Participating in asynchronous online discussions as a part of case-based learning can be challenging for learners. As learners participate in asynchronous online discussions, they may experience negative attitudes, lack of communication, and personal conflict with peers (Azer, 
2001). They are unable to judge facial cues of other participants when discussing problem elements, resulting in delayed responses and a drop in overall group learning (Anderson et al., 2008). Additionally, learners do not always see the relevance of case discussions, leading to a lack of motivation for active participation in the conversation (Beaudoin, 2002; Xie \& Huang, 2014; Xie, et al., 2011). Finally, learners have difficulty extending and deepening the conversation, leaving the outcomes of a discussion at a surface level (Hara et al., 2000) and difficulty in promoting higher order thinking (Hsiao et al., 2013). Therefore, not only does discussion structure and facilitation affect the learning process (Ertmer \& Koehler, 2015, 2019), how learners manage the inherent challenges of and choose to navigate an asynchronous online discussion while participating in case-based learning can also influence the value of the experience.

As asynchronous online discussions are constrained by pre-structured prompts created by instructors (Gao, 2014), learners must ultimately determine how to use the discussion within the parameters set by the instructor to monitor their problem solving - refining their understanding of complex problems and exploring solutions to identified case problems (Wu et al., 2013). Effective problem solvers understand the nature of a problem, select and apply previous knowledge relevant to the situation, evaluate the utility of the solutions, adjust their solutions and their mental model, and select the most effective solution (Jonassen, 1997). To effectively participate in discussions during case-based learning, learners arguably need to intentionally use the discussion to support their learning.

As learners determine how to participate in an online asynchronous discussion and use it to support their understanding of a case, they must simultaneously manage several tasks and make many decisions: identifying a goal for participation, selecting an appropriate time to enter a discussion and follow-up with peers, determining which peers to interact with, finding opportunities to join the conversation in meaningful ways, deciding how many discussion posts to read, adjusting personal strategies based upon the feedback from peers and the instructor, and managing challenges inherent of asynchronous online discussions. In other words, a learner's approach to navigating an asynchronous online discussion represents a problem-solving process, and the extent to which an individual learner can take advantage of the learning space afforded by a case discussion depends on the learner's ability to effectively problem solve. That is, just as an ill-structured problem is not well-defined and has many potential paths to success (Jonassen, 1997), learners should determine goals to guide their discussion participation and adopt strategies to meet these goals.

\section{Purpose}

While asynchronous online discussions have the potential to support learners as they make sense of complex case content, much of the potential value depends on the learners' actions. Thus, more research is needed to understand how learners intentionally use asynchronous online discussions during case-based learning. Considering learners' online discussion participation as an ill-structured problem-solving process, we explored the problem-solving strategies adopted by learners participating in online discussions to support their understanding during a case-based learning experience. Specifically, we considered the following research question: How do learners' online discussion approaches represent diverse problem-solving processes during case-based learning? 


\section{Methods}

\section{Research Design}

We used an exploratory multiple case study to consider the experiences of six students navigating three asynchronous online discussions during case-based learning (Kohlbacher, 2006; Yin, 2018). Case study research has constructivist underpinnings (Baxter \& Jack, 2008), which align well with problem-centered educational environments that are also constructivist in nature. Generally, a case study approach offers researchers the opportunity to consider contextual factors related to the phenomena under investigation (Yin, 2018). By considering multiple cases of learners' approaches to a case-based discussion, we were able to consider individual processes, compare processes across multiple learners (Baxter \& Jack, 2008), and construct a robust understanding of how discussion participation represents a problem-solving process and how these processes vary across learners.

In previous research from the same project, we found that individual students contributed at different levels when collaboratively problem solving during case-based asynchronous online discussions. We concluded that these differences were a result of personal approaches used to navigate asynchronous online discussions. Driven by this important finding, we reexamined the interview data from a different perspective in order to gain a deeper sense of the unique navigation efforts of students, which allowed us to analyze and describe individual processes. Case selection was based on literal and theoretical replication logic, that is, to select multiple individual cases that predict similar or contrasting results (Yin, 2018). To explore students' participation patterns, perceptions, motivations, and challenges when engaging in asynchronous online discussions as a part of case-based learning, we considered data from semi-structured interviews.

\section{Participants}

Participants included six of twelve graduate students (5 female, 1 male) enrolled in an advanced instructional design 8-week online course during Fall 2018. The gender ratio of participants was equivalent to the larger course composition (10:2). All participants had previously taken several online courses and had varying professional backgrounds that were related to teaching, instructional design, and academic administration (see Table 1).

Table 1

Demographic Information

\begin{tabular}{llclc}
\hline Pseudonym & Previous Professional Experiences & Gender & Level & Native English Speaker \\
\hline Deidra & $\bullet$ & F & M.S. & Yes \\
& $\bullet$ Administrative Assistant in & & & \\
Faith & - Higher Education & & & \\
& - Project Management & F & Ph.D. & No \\
& - Graduate Assistant & & & \\
Kevin & $\bullet$ ID Intern & M & M.S. & Yes \\
& $\bullet$ Teaching Assistant & & &
\end{tabular}




\begin{tabular}{|c|c|c|c|}
\hline Lisa & $\begin{array}{l}\text { - Instructional Designer in Higher } \\
\text { Education }\end{array}$ & $\mathrm{F}$ & M.S. \\
\hline Mary & $\begin{array}{l}\text { - Employee Training Specialist } \\
\text { - Teaching Assistant }\end{array}$ & $\mathrm{F}$ & Ph.D. \\
\hline Teresa & $\begin{array}{l}\text { - Teacher } \\
\text { - Director of Training Programs in } \\
\text { Higher Education }\end{array}$ & $\mathrm{F}$ & M.S. \\
\hline
\end{tabular}

\section{Context}

The study was conducted in an advanced instructional design course offered as part of an online learning design and technology program at a large Midwestern university. Students completed four primary course activities: case analyses ( $40 \%$ of final grade), online discussions ( $24 \%$ of final grade), student-group case facilitation ( $24 \%$ of final grade), and a final reflection on their developing expertise ( $12 \%$ of final grade). These assignments offered learners the opportunity to develop instructional design skills based on real-world cases. Specifically, students submitted a case analysis prior to participating in a weekly asynchronous online discussion.

Students participated in the discussion from Monday through Friday. Each weekly discussion consisted of two parts. The first half of the week was guided by an initial prompt focused on understanding case problems, while the second half of the week was guided by a second prompt focused on generating solutions to address identified problems. For instance, for the first discussion during the beginning of the week, students were asked to assume the role of key stakeholders to consider the problem from diverse perspectives. Then, in the second part of the discussion, students were asked to create solutions that would meet stakeholder needs. At the beginning of the course, students were given a rubric to guide participation efforts based on quality, quantity, timeliness, activeness across the discussion, and unique thread participation.

\section{Data Collection}

After the course ended, all students were sent an invitation to participate in a semistructured interview, and six students agreed to be interviewed. Prior to being interviewed, each student completed a Qualtrics survey asking them to share their professional background, previous online experience, and perceived value of discussions and specific strategies used during discussions. We used previous literature on problem-solving literature to inform the development of our interview protocol (Jacob \& Furgerson, 2012). Problem solving is described as having two main phases: problem representation (e.g., identifying the problem to be solved) and generation of solutions (e.g., creating solutions to identified problems; Ertmer \& Stepich, 2005; Eseryel et al., 2011). Using these major problem-solving phases as a guide, we developed interview questions focusing on the role and value of online discussions in case-based learning, the specific approach they used for entering and navigating a discussion, motivators and challenges, reasons behind participation decisions, and their use of specific strategies (see Appendix A for the complete interview protocol). Prior to interviewing participants, the protocol was piloted on two graduate students not in the class. Interviews took place both face-to-face and online, lasting approximately 45 to 60 minutes. Interviews were recorded and transcribed verbatim. 


\section{Data Analysis}

Using Jonassen's (1997) ill-structured problem-solving framework as a guide, we conceptualized the primary problem-solving steps in participating in an asynchronous discussion during case-based learning as including: (a) articulating the purpose of discussion participation (defining the problem space, stakeholder roles, and contextual constraints), (b) clarifying perspectives on the role of discussion (considering and interpreting alternative perspectives), (c) generating discussion participation and interaction strategies (creating solutions to defined problems), and (d) assessing discussion participation and interaction strategies (determining the value of and justifying proposed solutions). Together these steps represent a problem-solving process, and by using Jonassen's framework, we were able to represent how students defined the problem of participating in an online discussion and approached and addressed this problem.

Relevant comments from the interviews were coded as one of the four problem-solving steps by two members of the research team, and through discussion $100 \%$ agreement was reached. Next, all coded statements within each problem-solving phase were reanalyzed using descriptive coding, resulting in sub-themes within each problem-solving phase (see Appendix B for the coding schema and sample quotes). Using this data, we constructed individual profiles for each participant that captured their complete individual discussion navigation. From constructing these profiles, we were able to create six unique illustrations of students' problem-solving processes resulting from navigating an asynchronous online discussion.

\section{Results}

For each student, we constructed a conceptualization of the individual problem-solving process each adopted while participating in asynchronous online discussions as part of case-based learning (see Table 2 for student discussion participation data). Each conceptualization is represented by individual problem-solving phases (see Table 3 for a comparison of each problemsolving phase across student).

Table 2

Students' Participation Overview

\begin{tabular}{|c|c|c|c|c|c|}
\hline & \multicolumn{4}{|c|}{$\begin{array}{l}\text { Unique Thread } \\
\text { Participation }\end{array}$} & \multirow[b]{2}{*}{$\begin{array}{c}\text { Avg. Replies Generated } \\
\text { by Initial Prompt }\end{array}$} \\
\hline & $\begin{array}{c}\text { Avg. per } \\
\text { Discussion }\end{array}$ & $\begin{array}{l}\text { Total } \\
\text { Posts }\end{array}$ & $\begin{array}{l}\text { Avg. per } \\
\text { discussion }\end{array}$ & Total & \\
\hline Faith & 4.17 & 25 & 3.67 & 11 & 4.80 \\
\hline Kevin & 3.50 & 21 & 3.67 & 11 & 2.80 \\
\hline Mary & 6.00 & 36 & 3.67 & 11 & 9.20 \\
\hline Teresa & 10.83 & 65 & 8.00 & 24 & 8.80 \\
\hline Lisa & 3.17 & 19 & 4.00 & 12 & 2.60 \\
\hline Deidra & 4.17 & 25 & 4.00 & 12 & 5.40 \\
\hline
\end{tabular}




\section{Kevin's Problem-Solving Process}

\section{Articulating the Purpose of Discussion Participation}

Kevin's primary purpose for participating in discussions was to meet course requirements (e.g., "I have to get this posted by a certain time."). Also, he explained that another motivator was "feeling bad for those who post late." Kevin experienced several barriers: time management/ procrastination, difficulty with the online medium (e.g., "sarcasm does not exactly come across in written text too well"), the discussion structure (e.g., "It was a scroll after scroll... you've got 100 plus posts in one thread."), and finding a place to enter (e.g., "What do I even say?"). He viewed the instructor role as most important: "You want to take what they say with more significance than possibly others."

\section{Clarifying Perspectives on the Role of Discussion}

Kevin shared that discussions "played a role in further explaining the issue at hand" especially in more difficult cases, "slightly informed" future analyses, and "helped open" his mind to new possibilities. He also explained that discussions weren't "especially helpful," viewing them as "supplemental material" and not having "much impact." When considering the value of peers and instructors, he appreciated being able to discuss ideas "outside of the discussion" and peers" professional experiences. After feeling "overwhelmed" with the discussion, he emailed his instructor to express frustration with the discussion format, suggesting he valued her role in improving his situation.

\section{Generating Discussion Participation and Interaction Strategies}

Kevin explained his approach to meeting course discussion requirements in this way: "You just post whatever your thoughts are. They may be connected to someone else's; they may not." For subsequent posts, he targeted individuals he was familiar with, shared common philosophies, or found easy to interact with (e.g., "People who I felt like I shared something with"); felt obligated to respond to the instructors; and found posting on individuals with no response to be an "easy" entry strategy. For difficult discussion prompts, he reviewed peers' posts to "help generate ideas." He avoided peers he felt were too active in the discussion or ones that he did not know. To overcome time challenges, his strategy was to post "whenever I was available, just trying to get the bare minimum done."

\section{Assessing Discussion Participation and Interaction Strategies}

Kevin measured the effectiveness of discussion activity based upon earning all "discussion points." When posting as a result of interest, Kevin felt the frequency of his posts increased. While considering the value of peers' discussion contributions, he discussed the frequency of posts and how these posts affected the discussion: "I mean great like for the conversation, but your ideas kind of usually stopped and some people aren't able to contribute a lot." He attributed using specific discussion strategies to his busy schedule, staying within his comfort zone, and finding easy entry into the discussion. He offered the following response for improving his approach: "stop procrastinating and try to do more." 


\section{Deidra's Problem-Solving Process}

\section{Articulating the Purpose of Discussion Participation}

Deidra had two goals: to meet course requirements (e.g., "I made sure I did the minimum required discussion posts") and to use the discussion to gain insights from peers (e.g., "It was just really interesting to start to listen to the other students"). She experienced several challenges when participating: time constraints, feeling intimidated (e.g., "I was never going to rise to their level."), online format (e.g., "Unless you delete it, it's there."), reading long posts, and finding a way to enter. While Deidra considered the instructor's role as important in the discussion, she did not appear to see a prominent role for peers in the discussion: "I don't remember most of these people, and I didn't interact with any of them."

\section{Clarifying Perspectives on the Role of Discussion}

Deidra valued discussions as a way to check understanding (e.g., "I would realize I was way off.") and consider diverse perspectives (e.g., "The most influential thing probably would be reading other people's [posts]."). She felt instructors played an essential role in directing the process of her thinking. While she shared that she "enjoyed analyzing" peers" solutions, her views on the value of interactions are unclear: "There were just other people. I just either didn't know them, hadn't had very much interaction with them, or didn't really ever tend to agree with them." She was aware of a deeper relationship between her challenges and discussion value: "I had really understood the importance of interaction even though I didn't have a lot of time to do stuff."

\section{Generating Discussion Participation and Interaction Strategies}

Deidra described her participation approach in this way: "I'm not even going to look at theirs [peers posts]. I'm just going to look at the prompt, and I'm going to post how I feel like I should respond, and then hit submit. Then, I'll read other people's [posts]." In addition to the instructors, she interacted with peers she was "more familiar with," who responded to her, and peers she was drawn to: "I would look for those people's posts instead of just going from top to bottom and reading everything." To address constraints, Deidra would "stick to shorter posts," "pick and choose" her interactions, and avoid individuals she found intimidating. While Deidra was aware that more interaction could improve her learning experience, she did not describe intentional strategies to increase interactions.

\section{Assessing Discussion Participation and Interaction Strategies}

Deidra assessed her discussion participation by considering the length, timing, and style (e.g., "I don't think I asked very many questions") of posts. She assessed peers' participation using the following criteria: length, available time (e.g., "they would have so much time to do a lot of outside reading and research"), clarity (e.g., "some people were at a different level than I was"), and frequency (e.g., she "just dominated a lot of it"). She found her instructor's role-playing ability to be effective, but sometimes found a "disconnect" between weekly prompts. Deidra justified her participation based on her limited time, her compatibility with others (e.g., "I just don't think that way"), and staying within course requirements (e.g., after completing required posts, she "didn't feel bad" about posting "I agree"). To improve, Deidra believed she should invest more time, read more, and have more interactions. 


\section{Faith's Problem-Solving Process}

\section{Articulating the Purpose of Discussion Participation}

Faith's discussion goals consisted of being the first to post in the discussion and meeting course requirements. Constraints she expressed included: peers expressing superficial agreement (e.g., "Oh yes I agree with you. Oh that's an awesome idea."), peers not taking the course seriously, time constraints (e.g., "To write a good post for me, it takes half an hour), long posts (e.g., "one page long I was totally demotivated"), course format (e.g., "there weren't any right or wrong answers"), and competitiveness (e.g., "I was sometimes even mad at her... why you did this before me"). Faith saw her role in discussions as correcting peers, feeling "empowered" to offer "strong feedback" to peers she knew were "wrong." She believed her peers helped "solidify ideas" and the instructor role was not "crucial" for her participation.

\section{Clarifying Perspectives on the Role of Discussion}

Faith did not believe the discussion played a significant role in helping her find case problems or solutions and viewed it as a way to gain affirmation on her own ideas. While she did believe the discussion offered her "other ways" of approaching cases and gave her a "frame of reference" to "compare" herself to her peers, she did not value all peers as part of this process, noting that she would "never actually be interested in" some of her peers' personalities. However, she did seek feedback from a couple of peers and used her instructor "as a model" for providing feedback to peers. Although Faith had limited professional experience, she believed her arguments were quite strong.

\section{Generating Discussion Participation and Interaction Strategies}

Faith's approach started when completing assigned case readings. Then, she would "jump in early," "focus" on "certain people," search for areas with which she could disagree, and look for cues (e.g., "When I see someone with more expertise agreeing with something or disagreeing with something that will definitely make me reflect on how I understand"). Faith used a research technique she had learned to consider peers' posts: "I remember classifying them in my head." Faith adopted a detailed schedule each week, avoided late posters, and used efficient interaction methods (e.g., "I know that I could read one sentence and I could get the idea") to address constraints. Faith realized connections across areas, sharing that she kept peers' occupations in mind to help consider their perspectives.

\section{Assessing Discussion Participation and Interaction Strategies}

Faith compared her posts against her peers (e.g., "When I saw other people's solutions, I felt like I was actually quite good") and the course rubric. With peers' posts, Faith considered length, approach (e.g., "She just agreed because that was easier."), accuracy (e.g., "They are not careful with their words"), and interest (e.g., "That will make me read more posts"). Faith justified discussion participation by suggesting her personal approach was superior (e.g., "I felt that I had strong arguments because I read"), to gain feedback (e.g., posting early meant "many people will answer back to me"), to maintain her schedule, and because she knew her peers were "wrong." To improve her approach, Faith shared, "I could be more understanding, more compassionate, more empathetic." 


\section{Lisa's Problem-Solving Process}

\section{Articulating the Purpose of Discussion Participation}

Lisa's goals for participating in the discussion included meeting course requirements, broadening her perspective, and fine-tuning her skills. Lisa experienced the following challenges: time constraints (e.g., "I was working full time and going to grad school.), discussion format (e.g., "hard to look at, just because of the way that it expands and stuff on your screen"), and experience levels of peers (e.g., "I could tell that maybe she could use some mentoring"). She viewed the instructor role as significant (e.g., "without it, things can get, sort of, out of whack") and her role as reaching self-improvement (e.g., "I wasn't really concerned with my peers' understanding exactly").

\section{Clarifying Perspectives on the Role of Discussion}

Lisa believed the discussion offered opportunities for seeing diverse perspectives and checking her understanding (e.g., "checking my perspective and determining if I was on track") but did not believe it impacted performance on case analyses. While she valued interacting with peers (e.g., "viewpoint that would allow me to develop a better solution"), she did not trust all peers equally (e.g., "Whereas some people who were just not as experienced, I didn't really trust what they were saying as much") and respected the instructor role more than her peers ("I was more likely to take what they said and incorporate it into my own strategies").

\section{Generating Discussion Participation and Interaction Strategies}

Lisa described her approach in this way: "While in the beginning, I may have listened to my peers more, by the end, I was more just, kind of doing it on my own... I wasn't incorporating their perspective as much into my solution." She used discussion prompts to frame her initial post (e.g., "what I felt that the case was trying to highlight") and described her interactions as being guided by responding to "pick[ing] somebody who hadn't had a response yet," disagreeing and agreeing, and offering encouragement. She avoided posts "without any substance." Finally, she observed instructor interactions with others: "I would look at that feedback and ask, 'Does this apply to my discussion posts and my work?"”

\section{Assessing Discussion Participation and Interaction Strategies}

Lisa assessed her participation by the number of posts she made. When considering peers' posts she asked herself, "Where could they have improved, or what gaps can I identify?" to improve her skills. She also considered how peers (e.g., they "just filled in the details") and instructors (e.g., "that's kind out of left field") contributed to the larger discussion. Lisa justified most participation decisions on personal motives: "I felt I could depend upon and engage with and have more of a full conversation with." When asked how she could improve, Lisa explained "I'm not sure ... I mean, you could kind of bring in some outside sources, but I sometimes hesitate to do that. It seems like a number of people are overwhelmed." 


\section{Mary's Problem-Solving Process \\ Articulating the Purpose of Discussion Participation}

While Mary's main purpose for participating in discussions was to learn more content and skills, she also was concerned with fulfilling the course requirements. She experienced some challenges when participating: non-native English speaker (e.g., "I've read multiple times"), inferiority (e.g., "I don't want to make my post seem too naive or simple"), and finding an entry point (e.g., "They've already touched every aspect"). She considered the role of peers and instructors as resources for pushing her forward: "comments or suggestions or questions from my classmates and the instructors helped me to question myself." She also considered listening to different perspectives as a way to "broaden thoughts and think about the problems."

\section{Clarifying Perspectives on the Role of Discussion}

Mary valued discussions for receiving feedback on ideas and exposure to diverse ideas. She believed peer interactions helped strengthen her understanding: "sometimes other students provided questions or challenged me." She found her instructor was able to provide more focused guidance than her peers: "Her knowledge is very constructed, so the questions she asked, it's like, very case-orientated, so it's very specific... Sometimes my classmates, their questions, [and] feedback [are] kind of more general." She also realized how her personal experience or interest in the discussion prompts motivated her to "participate more actively."

\section{Generating Discussion Participation and Interaction Strategies}

Mary met her discussion goals by spending extra time reading (e.g., "I read like 80 to 90\% of posts") and taking notes while reading (e.g., "wrote down...phrases or some words that I didn't know"). She did not "want to be the first one to post" so that she could have more time reading others' posts and composing her initial post. She would interact with peers to "ask for clarification," "provide consensus," or offer "suggestions," but did not feel comfortable challenging ideas. She targeted peers that "she felt comfortable with" as a result of previous interactions. She also considered feedback given to peers resulting from other conversations she was observing. She avoided responding to any individual with "strong arguments" but "never missed her posts."

\section{Assessing Discussion Participation and Interaction Strategies}

Mary assessed her participation based on seeing improvement: "In the first two weeks, I labeled the wrong stakeholders. But when I accumulated more experiences, I did not have that." Although she explained that she was "not a very active person in the class," she constantly considered how to promote participation and interaction strategies to help her develop understanding and skills: "I am thinking how to make my answers, make my posts make sense to others." She was never critical of peers' strategies and believed instructors' efforts helped her "think deeply." When asking how to improve her participation, she said, "If I post earlier, I think I will have more comments or more feedback from my classmates." 


\section{Teresa's Problem-Solving Process}

\section{Articulating the Purpose of Discussion Participation}

Teresa had one primary goal for participating in case discussions: "a desire to understand more." The challenges she faced included discomfort resulting from perfectionism (e.g., "Even when I submitted my case analysis, I often just was uncomfortable with what I submitted. I couldn't wait for that discussion to start"), handling disagreement ("I found it a bit troubling sometimes when I knew someone was posting something that was just incorrect"), and struggled with sounding conversational (e.g., coming across as "a little too academic"). Teresa saw specific roles for herself (e.g., "If someone asks the question, I feel an obligation to respond"), her peers (e.g., "social construction process of solutions is really important"), and instructors (e.g., "push me in a direction that maybe my peers weren't able").

\section{Clarifying Perspectives on the Role of Discussion}

Teresa valued the "significant" role of discussion participation to affirm ideas and expand her thoughts: "Everybody thinks about things differently, and they bring their own experiences to figuring out problems. There were times when it was just like a light bulb came on, and I thought. I can't believe I missed that." She considered peer interactions to be "critical" to help her "redefine how [she] thought about the case" and valued posts that challenged her, made her laugh, or think of something differently. She appreciated that her instructors "asked really great guiding questions and without giving a solution." She believed that her professional experience allowed her to feel comfortable "talking about meeting the needs of diverse audiences."

\section{Generating Discussion Participation and Interaction Strategies}

Teresa adopted a research approach when participating, "synthesiz[ing] information" and using "other resources for support"-including internet research, personal experiences, lessons learned from other courses, and often shared outside resources. She intentionally responded to peers who addressed her posts and comments and offered different ideas (e.g., "provide extra push for to think through something differently"), resulting in interacting with a broad range of peers. She posted early and "checked the discussion board several times a day" to ensure that she did not miss any important information. She avoided individuals that she perceived as not taking the course "seriously."

\section{Assessing Discussion Participation and Interaction Strategies}

Teresa evaluated her performance by accuracy ("sometimes I was off target") while being mindful that multiple solutions were possible (e.g., "It's not necessarily that my solution was a wrong solution, but seeing alternatives helped"). She evaluated her peers' participation based on their abilities to adopt a conversational tone (e.g., "sounded like they were just really talking to me") and the soundness of their argument (e.g., "I noticed that a lot of my peers would just post sort of their intuitive ideas about things."). Teresa justified her choices by determining if they were helping her understand more. She believed that she could improve her performance with additional experience: "I kind of have a framework now I think for that. I think that framework would help me approach cases differently." 
Table 3

A Comparison of Problem-Solving Strategies Across Students

Articulating the

Discussion Purpose

Conceptualized

Problem

Defined Roles

Identified

Constraints

Conceptualized

Problem

Defined Roles

Identified

Constraints

\section{Kevin}

How can I meet course

requirements and include late

posters into the conversation?

no role defined for self or peers, but saw the instructor as the leader of the discussion

time management, procrastination, difficulty with the online medium and discussion structure, challenges with entering the discussion

\section{Mary}

How can I meet course

requirements and use

discussion to more deeply

understand the content, gain

feedback, and consider

different interpretations?

saw peers' role to provide feedback and offer affirmation; the instructor's role helped her broaden her perspective; and her role as expressing agreement, asking for agreement, and creating a positive community

as a non-native English

speaker, reading, comprehending, and responding was difficult; lacked confidence in her ideas; intimidated by ambitious peers; and difficulty with entering the discussion

\begin{tabular}{|l}
\hline Lisa \\
\hline How can I meet course
\end{tabular}
requirements and use the discussion to broaden my perspective and improve skills?

saw her role in the discussion as achieving her own selfimprovement, the instructor role to manage the discussion, and did not define a role for peers

time constraints, discussion format, and dealing with lessexperienced peers

\section{Deidra}

How can I meet course requirements and use the discussions to gain insights?

no role defined for self or peers, but saw the instructor as the leader of the discussion constraints, entering the discussion, and feelings of intimidation reading long posts, time

\section{Teresa}

How can I use the discussion to best understand the case and develop solutions with group input?

saw her and her peers' roles to share ideas to support a collaborative outcome, including a personal role to share resources, while she saw her instructor's role to push her out of her comfort zone and scaffold students' learning process

perfectionism, handling disagreement, individuals not taking the course seriously, and maintaining a conversational style

\section{Faith}

How can I meet course deadlines, earn full points, and be the first to post?

viewed her role as correcting peers, her peers' role as offering affirmation to her ideas, and did not believe the instructor played a crucial role in the discussion

superficial agreement, peers not taking the course seriously, time constraints, long posts, course format, and competitiveness 


\begin{tabular}{|c|c|c|c|}
\hline \multirow{2}{*}{$\begin{array}{l}\text { Clarifying } \\
\text { Perspectives on the } \\
\text { Role of Discussion }\end{array}$} & \multirow[b]{2}{*}{ Kevin } & \multirow[b]{2}{*}{ Mary } & \multirow[b]{2}{*}{ Teresa } \\
\hline & & & \\
\hline Use of Perspectives & $\begin{array}{l}\text { considered ideas of peers he } \\
\text { had established relationships } \\
\text { with to solidify understanding, } \\
\text { clarify a misunderstanding, and } \\
\text { meet course requirements }\end{array}$ & $\begin{array}{l}\text { interacted with peers to receive } \\
\text { answers to questions, to be } \\
\text { challenged, consider diverse } \\
\text { ideas, and to offer suggestions }\end{array}$ & $\begin{array}{l}\text { interactions offered } \\
\text { opportunities to consider new } \\
\text { ideas, redefine case problems, } \\
\text { push thinking, and improve } \\
\text { solutions }\end{array}$ \\
\hline Value of Discussions & $\begin{array}{l}\text { did not see discussions as very } \\
\text { helpful or impactful; } \\
\text { supplemental to individual } \\
\text { work }\end{array}$ & $\begin{array}{l}\text { enjoyed discussion, felt they } \\
\text { improved understanding and } \\
\text { English skills, and broadened } \\
\text { perspective }\end{array}$ & $\begin{array}{l}\text { saw discussion as a social } \\
\text { medium to construct } \\
\text { understanding }\end{array}$ \\
\hline \multirow[b]{2}{*}{ Use of Perspectives } & Lisa & Deidra & Faith \\
\hline & $\begin{array}{l}\text { offered a way to consider the } \\
\text { case from multiple } \\
\text { perspectives and check } \\
\text { understanding, but did not trust } \\
\text { all of her peers }\end{array}$ & $\begin{array}{l}\text { interacted to check } \\
\text { understanding and consider } \\
\text { diverse perspectives, but did } \\
\text { not feel a connection to most } \\
\text { of her peers }\end{array}$ & $\begin{array}{l}\text { used discussions to seek } \\
\text { feedback from selected peers, } \\
\text { offer feedback to peers, and } \\
\text { compare herself to peers }\end{array}$ \\
\hline Value of Discussions & $\begin{array}{l}\text { felt discussion did not impact } \\
\text { her work }\end{array}$ & $\begin{array}{l}\text { enjoyed discussions and saw } \\
\text { value for using it to find } \\
\text { solutions }\end{array}$ & $\begin{array}{l}\text { did not see the discussion of } \\
\text { significant value but did help } \\
\text { strengthen her ideas }\end{array}$ \\
\hline \multirow{2}{*}{$\begin{array}{c}\text { Generating } \\
\text { Discussion } \\
\text { Participation and } \\
\text { Interaction Strategies }\end{array}$} & & & \\
\hline & Kevin & Mary & Teresa \\
\hline Posting Strategies & $\begin{array}{l}\text { posted "whatever he had to } \\
\text { say," viewed what peers had } \\
\text { posted to "help generate ideas" }\end{array}$ & $\begin{array}{l}\text { read peers' posts first, located } \\
\text { outside resources, reread the } \\
\text { case and posts, and prepared } \\
\text { her initial post }\end{array}$ & $\begin{array}{l}\text { complete research, synthesize } \\
\text { information, share additional } \\
\text { resources, read most posts, and } \\
\text { check the discussion board } \\
\text { several times }\end{array}$ \\
\hline $\begin{array}{l}\text { Interaction } \\
\text { Strategies }\end{array}$ & $\begin{array}{l}\text { targeted individuals he was } \\
\text { familiar with and responded to } \\
\text { any instructor questions }\end{array}$ & $\begin{array}{l}\text { interacted with peers she knew } \\
\text { or felt a } \\
\text { connection with, read most } \\
\text { posts (many several times), and } \\
\text { interacted for clarification }\end{array}$ & $\begin{array}{l}\text { interacted with dedicated peers } \\
\text { that could help increase her } \\
\text { knowledge and push her in } \\
\text { new ways }\end{array}$ \\
\hline $\begin{array}{l}\text { Constraint } \\
\text { Strategies }\end{array}$ & $\begin{array}{l}\text { avoided individuals that he was } \\
\text { unfamiliar with or posted too } \\
\text { frequently }\end{array}$ & $\begin{array}{l}\text { extensively prepared to create } \\
\text { meaningful ideas }\end{array}$ & $\begin{array}{l}\text { avoided individuals that were } \\
\text { not invested in the learning } \\
\text { process }\end{array}$ \\
\hline
\end{tabular}




\begin{tabular}{|c|c|c|c|}
\hline & Lisa & Deidra & Faith \\
\hline Posting Strategies & $\begin{array}{l}\text { framed initial post with } \\
\text { prompts, answered all } \\
\text { questions in her thread, and did } \\
\text { not incorporate peers' ideas }\end{array}$ & $\begin{array}{l}\text { read prompt, posted how she } \\
\text { felt, and read other posts }\end{array}$ & $\begin{array}{l}\text { used assigned readings to form } \\
\text { arguments }\end{array}$ \\
\hline $\begin{array}{c}\text { Interaction } \\
\text { Strategies }\end{array}$ & $\begin{array}{l}\text { looked for posts without } \\
\text { responses and those she could } \\
\text { easily respond to }\end{array}$ & $\begin{array}{l}\text { responded to peers who replied } \\
\text { to her first, peers she felt a } \\
\text { connection with, or peers she } \\
\text { was most familiar with }\end{array}$ & $\begin{array}{l}\text { followed specific peers, } \\
\text { searched for areas where she } \\
\text { could disagree, and corrected } \\
\text { her peers }\end{array}$ \\
\hline $\begin{array}{l}\text { Constraint } \\
\text { Strategies }\end{array}$ & $\begin{array}{l}\text { avoided posts of less- } \\
\text { experienced peers }\end{array}$ & $\begin{array}{l}\text { read short posts and avoided } \\
\text { peers who intimidated her }\end{array}$ & $\begin{array}{l}\text { created a detailed schedule, } \\
\text { avoided late posters, and } \\
\text { skimmed posts }\end{array}$ \\
\hline
\end{tabular}

\section{Assessing Discussion Participation and Interaction Strategies}

Self-Assessment

Peer-Assessment

Justification

Self-Assessment

Peer-Assessment

Justification

Improvement

K

Kevin

assessed peers based on

frequency and the influence

these posts had on the

discussion

strategies were comfortable and easy

allowed her to see if she was on track and interacting with peers she knew was comfortable

Mary

improvement of ideas over time and level of activeness

quality of posts

posting earlier in the discussion to gain more feedback

\begin{tabular}{|ll|}
\hline Lisa & Deidra \\
\hline $\begin{array}{l}\text { number of posts and earning } \\
\text { points }\end{array}$ & $\begin{array}{l}\text { length of posts, timing, and } \\
\text { style }\end{array}$ \\
\hline
\end{tabular}

quality of posts and contribution to the discussion

followed course expectations, worked with limited time, and checked her understanding

no suggestions length, available time, clarity, and frequency

followed course expectations

invest more time, read more, and increase interactions and worked with limited time

\section{Teresa}

accuracy

conversational ability and soundness of argument

considered if selected strategies were leading to greater understanding

with additional experience, she believed she could improve her style

\section{Faith}

compared the validity of her posts with her peers and rubric

length, quality, accuracy, and engagement

superior personal approach, gained feedback, fit with schedule, and other posts were inaccurate increasing compassion towards peers 


\section{Discussion}

From constructing individual profiles, we were able to see six unique ways that individuals navigated asynchronous online discussions during case-based learning. Not only do these profiles offer insight into how the problem-solving process unfolds during asynchronous online discussions, but also how discussions can be designed to support case-based learning. As the nature of this research was exploratory, we discuss considerations by each problem-solving phase and offer suggestions for future research considerations.

\section{Articulating the Discussion Purpose}

When articulating the purpose of discussion participation, understanding case content was a secondary or nonexistent goal for many students. Instead, they predominantly relied on instructor-set course requirements to guide participation. Overall, many learners treated discussion participation as a well-structured problem instead of the ill-structured task that it is. On one hand, this makes sense. That is, when considering discussion participation, students viewed the role of the instructor as the most significant in the process, wanted to achieve specific grade outcomes, and followed the parameters set by the instructor. Previous research suggests the necessity of guidelines for facilitating effective asynchronous online discussions (Ballantine, 2005; Lee et al., 2009; Pena-Shaff \& Nicholls, 2004) and the effect that these guidelines can have on learners' performance (Pena-Shaff, 2015). In this research, the guidelines clearly shaped the resulting discussions. On the other hand, in problem-centered learning, students share responsibility in coconstructing understanding with peers and the instructor (Ertmer \& Newby 2016), and while students appeared to have clearly articulated roles for the instructors, some did not appear to fully consider their role or their peers' roles in sharing ownership in this process. At the same time, some students adopted roles that could be unproductive (e.g., providing very strong feedback to peers). If students are relying predominantly on discussion guidelines to set the direction without simultaneously considering personal goals and embracing the role of a co-constructor, discussion outcomes may not be as robust as they could be. This finding aligns with other research suggesting that students may be ill-prepared for "e-learning environments situated within the social constructivist paradigm," needing more training in order to gain full benefits (Parkes et al., 2015).

Similar to other research suggesting that learners experience challenges when participating in asynchronous online discussions (Anderson et al., 2008; Azer, 2001; Beaudoin, 2002; Xie \& Huang, 2014), learners in this research experienced time constraints, challenges with the online medium and discussion structure, difficulties finding a place to enter, and problems with peer conflicts. While some of these challenges were beyond the learners' control (e.g., LMS features and discussion forum structure), other challenges (e.g., procrastination, handling disagreement) represent areas where learners' skills are perhaps underdeveloped. Previous research suggests that instructors play a significant role in facilitating meaningful outcomes in a case-based discussion (Ertmer \& Koehler, 2014; 2015). However, future research and implementations should consider how instructors can simultaneously support students' goal creation in navigating an asynchronous online discussion, while handling challenges and considering case content. Finally, when creating asynchronous online discussions during case-based learning, instructors should consider asking students to articulate participation goals upfront, which can help learners' monitor their problem solving (Wu et al., 2013). Perhaps, by setting goals, learners can reduce some of the challenges they are experiencing. 


\section{Clarifying Perspectives on the Role of Discussion}

Students expressed differing levels of value for participating in discussions. In some cases, students possibly missed the value of discussions in the case-based learning process and supporting their personal learning. Although previous research suggests that discussion is an important part of the case-based learning process (Goeze et al., 2014; Gravett et al., 2017; Koehler et al., 2019), without seeing the relevance of this course activity, some students were likely not motivated to be an active participant in the conversation (Beaudoin, 2002; Xie \& Huang, 2014; Xie et al., 2011). To boost the value students perceive from discussion participation during case-based learning, instructors should consider strategies that help learners realize how asynchronous online discussions can improve understanding. For instance, previous research suggests that asynchronous online discussions play an important role in supporting the development of learners' problem-solving during case-based learning (Goeze et al., 2014; Gravett et al., 2017; Koehler et al., 2019). Therefore, when introducing asynchronous online discussions as a class activity, instructors may consider creating a video introduction highlighting specific research, testimonials, and other examples underscoring how asynchronous online discussions can support the development of important skills.

Additionally, students expressed several ways that they benefited from peer and instructor interactions (e.g., receiving feedback, being pushed to consider content more deeply, improving on own responses) during asynchronous online discussions. However, some students were reluctant to trust the ideas of their peers or valued only interactions with peers with whom they were familiar. While previous research suggests that students' consideration of peers' posts is part of the asynchronous online discussion process (Pena-Shaff \& Altman, 2009) and contemplating the value of peers' contributions can be helpful in effectively navigating a discussion, these judgments can simultaneously be limiting. For example, if learners begin to devalue specific participants' contributions to a discussion, especially for superficial reasons (e.g., "I just didn't know them"), then, likely learners will miss considering diverse viewpoints and receiving full benefits from a discussion. To address this concern, instructors could require students to interact with one or more individuals that they had not previously interacted with or incorporate introductory activities that help learners realize mutual connections and interests. At the same time, in problem-centered learning environments like the one in this study, "regulating learning is rarely a solitary task" (Häkkinen et al., 2016, p. 30). To help students' best use diverse perspectives while participating in case-based discussions, they arguably need support in developing skills to socially regulate their learning.

\section{Generating Discussion Participation and Interaction Strategies}

Students used a variety of strategies to meet discussion participation goals (e.g., completing outside research before responding, finding peers without replies, targeting a few individuals to consider their responses). Although we did not measure the effectiveness of these strategies, some were more intentional (e.g., "post whatever your thoughts are" vs. "I spent lots of time preparing for my initial post") and more visible than others (e.g., learning from observations of peers' interactions). In this research, for some students, much of what drove decision-making was not related to case-based learning - instead their participation strategies focused on meeting course requirements, talking with people they like, and finding easy entry into the conversation. While these strategies may be useful in promoting a social connection among some peers (Blackmon, 2012), used without specific strategies that connect with the outcomes of case-based learning likely limited the discussions (Pena-Shaff \& Altman, 2009). Effective solutions are focused on clearly 
articulated problems (Jonassen, 1997). In this study, many learners did not have well-articulated goals, and the limitedness of their strategies is potentially related to a lack of setting a clear direction beyond course requirements.

When discussing asynchronous online discussion participation, students described several constraints (e.g., time, peer conflict); yet, they offered few strategies for overcoming these challenges. In other words, some learners seemed willing to accept the constraints instead of finding ways to overcome these challenges. Likely, if learners more successfully managed constraints, they would have felt more positive towards the experience which could have affected the entire learning process. Overall, while students were able to find strategies to meet course requirements, how much they benefited from the experience is unclear. Similar to other research focused on the role of discussions during case-based learning, this research suggests that learners tried to make sense of complex topics through combining their own previous knowledge and experiences with course content, while relying on some of their peers' judgments (Choi \& Lee, 2009; Mostert, 2007). However, learners did not leverage the flexible nature of asynchronous online discussions for reflecting and revisiting posts (Cheung \& Hew, 2004; Garrison et al., 2001; Putnam et al., 2012; Rovai \& Jordan, 2004; Wu et al., 2013), instead often focusing on meeting the "bare minimum" course requirements. To help students realize the benefit of unique asynchronous online discussion affordances, instructors can design opportunities for students to revisit and reflect upon posts, in order to boost critical thinking and problem-solving skills.

\section{Assessing Discussion Participation and Interaction Strategies}

While some students assessed their participation efforts based on improvement or accuracy, many students assessed personal participation in the case discussions based on the guidelines set by the instructor. That is, they often described successful outcomes in terms of earning points, frequency and timing of posts, or adherence to the discussion rubric. At the same time, some students' assessment of their peers' posts was more critical than how they assessed themselves. For instance, Kevin felt that one of his peers' posting approach limited the ability for others to share. However, he did not appear to consider how his lengthy, late, or disconnected posts potentially affected the conversations.

While using discussion guidelines can be useful for setting a desired level of participation (Pena-Shaff, 2015), for asynchronous online discussions to serve the most effective role in problem-centered learning, students should share ownership in the evaluation process. For instance, Lisa felt that her critical thinking and problem-solving skills developed over time. At the beginning of the course, she relied on her peers' posts before arriving at possible solutions to case problems; however, by the end of the course, she stopped incorporating others' perspectives in her solutions. While her perceived self-growth is promising, how she measured her growth is unclear, and the fact that she stopped considering diverse perspectives is troubling. Finally, when learners were asked how they might improve upon their approach to participating in discussions, many seemed uncertain how best to do that, suggesting general ideas (e.g., "stop procrastinating," "if I had more time to read more") lacking a connection to the results of a meaningful self-assessment and missing specific steps to achieve improvement. Students that are able to accurately assess their abilities can more effectively manage a learning process (Rivers, 2001), and students relying primarily on preset guidelines to determine the effectiveness of their performance are failing to fully self-assess. Instructors facilitating asynchronous online discussions are in a tough position: Without the guidelines, students are unlikely to actively participate, but overreliance on the 
guidelines could prevent learners from exploring more meaningful evaluation methods. More research is needed to determine how students can share ownership in the evaluation process.

\section{Limitations and Future Research}

In this research, we considered the perspectives of students in order to conceptualize asynchronous online discussion participation as a problem-solving process. Although there are similarities across problem-solving phases for students, each complete problem-solving process represents a unique path. More research is needed to determine how these decisions affect course performance. The exploratory nature of this research offers direction for future research. First, while this research revealed differences in individual approaches, we are unable to link these differences to students' learning performance. Future research should investigate the relationship between problem-solving processes adopted by learners participating in asynchronous online discussions and learning outcomes. Additionally, case-based learning can be facilitated in many ways, and this research considers learners' experience in a single context. Participants' interview data revealed that course structure and design factors influenced their resulting problem-solving process. However, the extent that contextual factors and design choices affected students' choices is unclear. Future research should consider how learners' problem-solving is impacted by course structure and discussion facilitation strategies and which instructional strategies lead to the most effective discussion navigation. Finally, this research considered the perspective of six graduate students. Whether research in other contexts with students at different levels (e.g., undergraduate) would lead to similar outcomes is unclear. Similar research in different contexts would offer insight as to how problem-solving in discussions unfolds in other environments.

\section{Conclusion}

Overall, in this advanced case-based course, some students did not have advanced discussion-navigation skills, and similar to other research (Häkkinen et al., 2016), the students did not appear prepared to deal with the complexity involved in an environment that required a shared ownership among members. Perhaps, instructors expect that students naturally develop these skills over time. However, this research suggests that instructors and students sometimes have a different understanding of the purpose a case discussion and that students need more guidance on how best to navigate a case discussion as a shared social experience. Additionally, the findings from this research indicate that how much learners gain from working with others depends on how they value the collaborative process. Previous research suggests that a collaborative element during problem-centered learning does not enhance the experience (Wirkala \& Kuhn, 2011), and our research provides insight as to why this might be the case for all individuals. This research provides a conceptualization of how asynchronous online discussions represent a problem-solving process for learners. From this conceptualization, we have created a foundation for exploring how specific problem-solving phases resulting from the navigation of asynchronous online discussions can be further investigated and supported. As many researchers agree that discussion comprises an important element during case-based learning (Goeze et al., 2014; Gravett et al., 2017), determining how to best support learners as they navigate discussions is worthwhile in order to boost the effectiveness of the entire method. 


\section{References}

Anderson, W. L., Mitchell, S. M., \& Osgood, M. P. (2008). Gauging the gaps in student problemsolving skills: Assessment of individual and group use of problem-solving strategies using online discussions. CBE-Life Sciences Education, 7(2), 254-262.

Azer, S. A. (2001). Problem based learning: Challenges, barriers and outcome issues. Saudi Medical Journal, 22(5), 389-397.

Baars, M., Vink, S., van Gog, T., de Bruin, A., \& Paas, F. (2014). Effects of training self-assessment and using assessment standards on retrospective and prospective monitoring of problem solving. Learning and Instruction, 33, 92-107.

Ballantine J. (2005, November). What didn't work and why? Failed teaching attempts and what to do about them [Conference presentation]. Lilly Conference on College Teaching, Oxford, $\mathrm{OH}$, United States.

Beaudoin, M. F. (2002). Learning or lurking? Tracking the "invisible" online student. The Internet and Higher Education, 5(2), 147-155. doi:10.1016/S1096-7516(02)00086-6

Blackmon, S. (2012). Outcomes of chat and discussion board use in online learning: A research synthesis. Journal of Educators Online, 9(2), 2.

Cheung, W. S., \& Hew, K. F. (2004). Evaluating the extent of ill-structured problem solving process among pre-service teachers in an asynchronous online discussion and reflection log learning environment. Journal of Educational Computing Research, 30(3), 197-227.

Choi, I., \& Lee, K. (2009). Designing and implementing a case-based learning environment for enhancing ill-structured problem solving: Classroom management problems for prospective teachers. Educational Technology Research \& Development, 57(1), 99-129.

Ertmer, P. A., \& Koehler, A. A. (2018). How context affordances shape facilitation strategies and problem-space coverage: Comparing face-to-face and online case-based discussions. Educational Technology Research and Development, 66(3), 639-670.

Ertmer, P. A., \& Koehler, A. A. (2015). Facilitated vs. non-facilitated online case discussions: Comparing differences in problem space coverage. Journal of Computing in Higher Education, 27(2), 69-93.

Ertmer, P.A., \& Koehler, A. A. (2014). Online case-based discussions: Examining coverage of the afforded problem space. Educational Technology Research and Development, 62(5), 617636.

Ertmer, P. A., \& Newby, T. J. (2016). Learning theory and technology: A reciprocal relationship. In N. Rushby \& D. W. Surry (Eds.), The Wiley Handbook of Learning Technology (pp. 58-76). Wiley.

Ertmer, P. A., \& Stepich, D. A. (2005). Instructional design expertise: How will we know it when we see it? Educational Technology, 45(6), 38-43.

Eseryel, D., Ge, X., Ifenthaler, D., \& Law, V. (2011). Dynamic modeling as a cognitive regulation scaffold for developing complex problem-solving skills in an educational massively multiplayer online game environment. Journal of Educational Computing Research, 45(3), 265-286. 
Galustyan, O. V., Borovikova, Y. V., Polivaeva, N. P., Kodirov, B. R., \& Zhirkova, G. P. (2019). Elearning within the field of andragogy. International Journal of Emerging Technologies in Learning, 14(9), 148-156.

Gao, F. (2014). Exploring the use of discussion strategies and labels in asynchronous online discussion. Online Learning, 18(3), 1-19.

Garrison, D. R., Anderson, T., \& Archer, W. (2001). Critical thinking, cognitive presence, and computer conferencing in distance education. American Journal of Distance Education, 15(1), 7-23. doi:10.1080/08923640109527071

Goeze, A., Zottmann, J. M., Vogel, F., Fischer, F., \& Schrader, J. (2014). Getting immersed in teacher and student perspectives: Facilitating analytical competence using video cases in teacher education. Instructional Science, 42(1), 91-114.

Gravett, S., de Beer, J., Odendaal-Kroon, R., \& Merseth, K. K. (2017). The affordances of casebased teaching for the professional learning of student-teachers. Journal of Curriculum Studies, 49(3), 369-390.

Hara, N., Bonk, C. J., \& Angeli, C. (2000). Content analysis of online discussion in an applied educational psychology course. Instructional Science, 28(2), 115-152.

Häkkinen, P., Järvelä, S., Mäkitalo-Siegl, K., Ahonen, A., Näykki, P., \& Valtonen, T. (2017). Preparing teacher-students for twenty-first-century learning practices (PREP 21): A framework for enhancing collaborative problem-solving and strategic learning skills. Teachers and Teaching, 23(1), 25-41.

Hew, K. F., Cheung, W. S. \& Ng, C. S. L. (2010). Student contribution in asynchronous online discussion: a review of the research and empirical exploration. Instructional Science, 38, 571-606. https://doi.org/10.1007/s11251-008-9087-0

Hofsten, A., Gustafsson, C., \& Häggström, E. (2010). Case seminars open doors to deeper understanding-Nursing students' experiences of learning. Nurse Education Today, 30(6), 533-538. https://doi.org/10.1016/j.nedt.2009.11.001

Hsiao, W. Y., Chen, M. W., \& Hu, H. W. (2013). Assessing online discussions: Adoption of critical thinking as a grading criterion. International Journal of Technology, Knowledge, and Society, $9(3), 15-25$.

Jacob, S. A., \& Furgerson, S. P. (2012). Writing interview protocols and conducting interviews: Tips for students new to the field of qualitative research. Qualitative Report, 17(42).

Jonassen, D. H. (1997). Instructional design models for well-structured and ill-structured problemsolving learning outcomes. Educational Technology Research and Development, 45(1), 6594. http://dx.doi.org/10.1007/BF0229 9613

Jonassen, D. H. \& Hernandez-Serrano, J. (2002). Case-based reasoning and instructional design: Using stories to support problem solving. Educational Technology Research \& Development, $50(2), 65-77$.

Koehler, A. A., Ertmer, P. A., \& Newby, T. J. (2019). Developing pre-service teachers' instructional design skills through case-based instruction: Examining the impact of discussion format. Journal of Teacher Education, 70(4), 319-334. 10.1177/0022487118755701 
Kohlbacher, F. (2006). The use of qualitative content analysis in case study research. Forum Qualitative Sozialforschung/Forum: Qualitative Social Research, 7(1), 1-30. http://dx.doi.org/10.17169/fqs-7.1.75

Lee, S.-H., Lee, J., Liu, X., Bonk, C. J., \& Magjuka, R. J. (2009). A review of case-based learning practices in an online MBA program: A program-level case study. Part of a special issue: Technology Support for Self-Organized Learners, 12(3), 178-190.

Missett, T. C., Reed, C. B., Scot, T. P., Callahan, C. M., \& Slade, M. (2010). Describing learning in an advanced online case-based course in environmental science. Journal of Advanced Academics, 22(1), 10-50.

Moore, M. G. (2013). The theory of transactional distance. In Handbook of Distance Education (2nd ed.), (M.G. Moore, Ed.). Routledge. (pp. 84-103).

Mostert, M. P. (2007). Challenges of case-based teaching. The Behavior Analyst Today, 8(4), 434. https://files.eric.ed.gov/fulltext/EJ821490.pdf.

Pena-Shaff, J. (2015). Student interaction and knowledge construction in case-based learning in educational psychology using online discussions: The role of structure. Journal of Interactive Learning Research, 26(3), 307-329

Pena-Shaff, J., \& Altman, W. (2009). Case-based instruction using asynchronous online discussions: A synthesis. Journal on Excellence in College Teaching, 20(3), 97-121.

Pena-Shaff, J. B., \& Nicholls, C. (2004). Analyzing student interactions and meaning construction in computer bulletin board discussions. Computers \& Education, 42(3), 243-265.

Putman, S. M., Ford, K., \& Tancock, S. (2012). Redefining online discussions: Using participant stances to promote collaboration and cognitive engagement. International Journal of Teaching and Learning in Higher Education, 24(2), 151-167.

Ringler, I., Schubert, C., Friestad-Tate, J., Deem, J., Lockwood, R. \& Flores, J. (2015). Improving the asynchronous online learning environment using discussion boards. Journal of Educational Technology, 12(1), 15-27.

Rivers, W. P. (2001). Autonomy at all costs: an ethnography of metacognitive self-assessment and self-management among experienced language learners. Modern Language Journal, 85(2), 279-290. https://doi-org.ezproxy.lib.purdue.edu/10.1111/0026-7902.00109

Rovai, A., \& Jordan, H. (2004). Blended learning and sense of community: A comparative analysis with traditional and fully online graduate courses. International Review of Research in Open and Distance Learning, 5(2), 2-13. http://www.irrodl.org/index.php/irrodl/article/view/192

Schraw, G., Kauffman, D., \& Lehman, S. (2002). SRL theory. In J. Levin (Ed.), Encyclopedia of cognitive science. Macmillan.

Schwartz, P. L., Egan, A. G., \& Heath, C. J. (1994). Students' perceptions of course outcomes and learning styles in case-based courses in a traditional medical school. Academic Medicine, 69(6), 507.

Tainsh, R. (2016). Thoughtfully designed online courses as effective adult learning tools. $M P A E A$ Journal of Adult Education, 45(1), 32-37.

Tawfik, A. A. (2017). Do cases teach themselves? A comparison of case library prompts in supporting problem-solving during argumentation. Journal of Computing in Higher Education, 29(2), 267-285. 
Tawfik, A. A., \& Jonassen, D. (2013). The effects of successful versus failure-based cases on argumentation while solving decision-making problems. Educational Technology Research \& Development, 61(3), 385-406. doi:10.1007/s11423-013-9294-5

Tawfik, A. A., \& Kolodner, J. L. (2016). Systematizing scaffolding for problem-based learning: A view from case-based reasoning. Interdisciplinary Journal of Problem-Based Learning, 10(1). https://docs.lib.purdue.edu/ijpbl/vol10/iss1/6/

Tawfik, A. A., Reeves, T. D., Stich, A. E., Gill, A., Hong, C., McDade, J., ... \& Giabbanelli, P. J. (2017). The nature and level of learner-learner interaction in a chemistry massive open online course (MOOC). Journal of Computing in Higher Education, 29(3), 411-431.

Weltzer-Ward, L. (2011). Content analysis coding schemes for online asynchronous discussion. Campus-Wide Information Systems, 28(1), 56-74. https://doi.org/10.1108/10650741111097296

Winne, P. H. (1996). A metacognitive view of individual differences in SRL. Learning and Individual Differences, 8, 327-353.

Wirkala, C., \& Kuhn, D. (2011). Problem-based learning in K-12 education: Is it effective and how does it achieve its effects? American Educational Research Journal, 48(5), 1157-1186.

Wu, S. Y., Hou, H. T., Hwang, W. Y., \& Liu, E. Z. F. (2013). Analysis of learning behavior in problem-solving-based and project-based discussion activities within the seamless online learning integrated discussion (SOLID) system. Journal of Educational Computing Research, $49(1), 61-82$.

Xie, K., \& Huang, K. (2014). The role of beliefs and motivation in asynchronous online learning in college-level classes. Journal of Educational Computing Research, 50(3), 315-341. https://doi.org/10.2190/EC.50.3.b

Xie, K., Durrington, V., \& Yen, L. L. (2011). Relationship between students' motivation and their participation in asynchronous online discussions. MERLOT Journal of Online Learning and Teaching, 7(1), 17-29.

Yadav, A., Bozic, C., Gretter, S., \& Nauman, E. (2015). Benefits and challenges of implementing case-based instruction: A Student perspective. International Journal Of Engineering Education, 31(6), 1554-1563. https://purdue-primoprod.hosted.exlibrisgroup.com/permalink/f/1c3q7im/TN_wos000366351400012

Yadav, A., Lundeberg, M., DeSchryver, M., Dirkin, K., Schiller, N. A., Maier, K., \& Herreid, C. F. (2007). Teaching science with case studies: A national survey of faculty perceptions of the benefits and challenges of using cases. Journal of College Science Teaching, 37(1), 34-38. https://link.gale.com/apps/doc/A169164872/PROF?u=purdue_main\&sid=PROF\&xid=a00c3 $\underline{643}$

Yin, R. K. (2018). Case study research: Design and methods. Sage.

Zhu, E. (2006). Interaction and cognitive engagement: An analysis of four asynchronous online discussions. Instructional Science, 34, 451-480. doi:10.1007/s11251-006-0004-0 


\section{Appendix A \\ Pre-Survey}

1. How many courses have you taken online?

2. How would you rate your comfort level with learning in an online environment? Highlight one.

\begin{tabular}{|c|c|c|c|c|}
\hline $\begin{array}{c}\text { Very } \\
\text { Comfortable }\end{array}$ & $\begin{array}{c}\text { Somewhat } \\
\text { Comfortable }\end{array}$ & $\begin{array}{c}\text { Neither } \\
\text { Comfortable or } \\
\text { Not Comfortable }\end{array}$ & $\begin{array}{c}\text { Somewhat Not } \\
\text { Comfortable }\end{array}$ & $\begin{array}{c}\text { Very Not } \\
\text { Comfortable }\end{array}$ \\
\hline
\end{tabular}

3. Approximately, what percentage of posts did you read during a typical case discussion (e.g., $50 \%)$ ?

4. Approximately, how many times did you post in a typical case discussion (e.g., 5 times)?

5. Before creating your initial post in a case discussion, did you first read peers' posts?

Highlight one.

$\square$ Yes
$\square$ Sometimes
$\square$ No

6. Considering all of the case assignments you completed during 672 , which of the following do you believe was most helpful in strengthening your skills to identify ID problems and suggest potential solutions? Highlight one.
$\square$ Case Analyses
Case Discussions
Case Facilitation
ID Expertise Reflection

7. During a typical case discussion, which of the following factors helped you understand case problems and potential solutions? Highlight all that apply.

$\square$ Interaction with peers

Interaction with instructor

Initial discussion prompts

Additional resources shared in the discussion

Other: [Please include details here]

8. Do you feel that you will use anything from the case discussions in your future professional life?
$\square$ Yes
$\square$ Undecided
$\square$ No

9. If you were to give yourself a descriptive title of your role in a typical case discussion, what would it be? (In short, how would describe your participation? 1 to 2 sentences at most)

10. What is your professional background? Briefly list professional experience. 


\section{Interview Protocol}

\section{Questions}

1. During 672, you were asked to analyze several cases and suggest solutions to the problems in these cases. How would you describe the general role discussion played in supporting your understanding of case content, the instructional design problems considered in these cases, and specific solutions?

- Did participating in case discussions help you have a deeper understanding of the instructional design problems covered in the cases? (If they say yes, ask the next question. If they say no, ask them to explain). Could you describe how participating in discussions helped you identify ID problems in the cases you were analyzing?

- Did participating in case discussions help you have a deeper understanding of the effective solutions that would address the problems covered in the cases? (If they say yes, ask the next question. If they say no, ask them to explain). Could you describe how participating in discussions helped you create solutions?

2. Could you describe how you generally approached a case discussion or decided to participate in a case discussion? For instance, let's look at your participation in a previous case (pick one of the following cases ahead of time: Craig Gregersen, Michael Bishop, Lynn Dixon), how would you describe the major steps in this discussion approach process?

Follow-up Questions

- How did you determine how and when to jump into the conversation?

- How did you decide to frame your initial post?

- What influenced your decision to interact in the discussion board following your initial post?

- Do you think there are limitations to how you decides to participate in a case discussion? If so, what were these and why do you see them as limitations?

3. Across case discussions, were there any factors that motivated you to participate in the discussion?

4. Across case discussions, were there any factors that prevented you from participating in the discussion?

5. Would you say that these motivating factors helped your abilities to understand case content and create solutions? Or, prevented you from understanding case content or creating solutions?

(Note: On questions 3 and 4, give them room to respond. After their initial response, you can ask them about peer interaction, instructor interaction, instructor prompts, discussion structure, etc. as impacting one way or the other. Let them think about it first and then move into 5.) 
6. When participating in a typically case discussion, how did you decide who you would interact with or respond to?

- Are there certain people you typically were interested in reading their posts? If so, why?

- Are there certain people whose posts you tended to avoid? If so, why?

7. In your pre-interview, you said that you read approximately $<$ percentage $>$ of all posts and posted about $<\#$ of posts $>$ in a typical case discussion.

- What factors influenced the number of posts that you read?

- What factors influenced whether you responded to another post?

8. In your pre-interview, you shared that you $<$ did, did not, sometimes $>$ read your peers' posts before creating your own. Can you share a little more on this process? Why did you choose to $<$ read, not read, sometimes read $>$ before jumping into the conversation?

9. Considering the typical number of posts that you read and the typical number of posts that you composed-which carried a greater influence: course participation requirements or your understanding of case content? Can you talk about this a little?

10. In your pre-interview, you described your role in a typical discussion like this: $<$ repeat interviewee's role $>$. We would like to talk a little more about this:

- How would you classify the typical posts you make? For instance, do you tend to share agreement, to challenge a peer's idea, to ask clarifying questions?

- Are you more comfortable proposing a solution or do you prefer to analyze a suggested solution?

- Are you comfortable sharing personal experiences that match the case?

- How does instructor and peer feedback influence your participation in a case discussion?

- Earlier, you shared that you typically reading < names'> post and avoided $<$ names'> posts. How would you describe these individuals' roles in the discussion?

11. Would you describe your participation in a case discussion different than your participation in a non-case online discussion? Why or why not? 


\section{Appendix B}

\begin{tabular}{|c|c|c|}
\hline Problem-Solving Phase & Description of Subthemes & Examples \\
\hline $\begin{array}{l}\text { Articulating the } \\
\text { Purpose of Discussion } \\
\text { Participation } \\
\text { Identifying the purpose } \\
\text { of participation and } \\
\text { interaction, constraints } \\
\text { and benefits affecting } \\
\text { participation and } \\
\text { interaction }\end{array}$ & $\begin{array}{l}\text { - Statements that identify students' } \\
\text { goal(s) or purpose for participating } \\
\text { and/or interacting in the discussion } \\
\text { - Statements that describe challenges for } \\
\text { participating in the discussion } \\
\text { - Statements that describe stakeholder } \\
\text { (e.g., self, peers, instructors, others) } \\
\text { roles in the discussion process }\end{array}$ & $\begin{array}{l}\text { Usually, the reason I jumped in was mostly } \\
\text { because "I have to get this posted by a } \\
\text { certain time" } \\
\text { And the other one is from a structure of how } \\
\text { discussion boards are put together. I think } \\
\text { that they are super structured now and I } \\
\text { think if I can draw back on other } \\
\text { experiences, } \\
\text { I mean being the teacher's pet- people } \\
\text { pleaser that I am, I always try to take what } \\
\text { instructor says as a more significant idea- } \\
\text { than, probably would a peer with say. Even } \\
\text { if a peer has you know- more work } \\
\text { experience like- but they're the instructor- I } \\
\text { think that is a conditioning with the } \\
\text { education system. }\end{array}$ \\
\hline $\begin{array}{l}\text { Clarifying Perspectives } \\
\text { on the Role of } \\
\text { Discussion } \\
\text { Identifying, explaining, } \\
\text { and clarifying personal } \\
\text { and alternative } \\
\text { participation and } \\
\text { interaction approaches }\end{array}$ & $\begin{array}{l}\text { - Statements that describe the value of } \\
\text { stakeholder perspectives } \\
\text { - Statements that consider the relationship } \\
\text { between personal challenges and } \\
\text { participation strategies }\end{array}$ & $\begin{array}{l}\text { So I think, at least in my experience, } \\
\text { discussion have played a role in further } \\
\text { explaining the issue at hand. I think for me } \\
\text { personally at least I tend to do a lot of } \\
\text { internal/internalized thinking and processing } \\
\text { where as I don't tend to speak out and } \\
\text { discuss as much. I tend to understand things } \\
\text { more so in that way- so discussion aren't } \\
\text { especially helpful for me because as a } \\
\text { personal thing and understanding. } \\
\text { So I used her specifically as a model, how to } \\
\text { destroy well, give feedback, quote unquote } \\
\text { to my peers. } \\
\text { But by then I had really understood the } \\
\text { importance of interaction. And even though } \\
\text { I didn't have a lot of time to do stuff } \\
\text { working full-time and being a single mom, I } \\
\text { had a hard time finding the time to really, } \\
\text { really engage like some people did. }\end{array}$ \\
\hline $\begin{array}{l}\text { Generating Discussion } \\
\text { Participation and } \\
\text { Interaction Strategies } \\
\text { Identifying strategies } \\
\text { used to reach } \\
\text { participation and } \\
\text { interaction goals and }\end{array}$ & $\begin{array}{l}\text { Statements that describe strategies used } \\
\text { to achieve personal discussion goals or } \\
\text { to gain the most benefits from } \\
\text { participating }\end{array}$ & $\begin{array}{l}\text { And then as far as [like] getting into other } \\
\text { conversations with other people's posts, I } \\
\text { would say I tended to look at people's posts } \\
\text { who were aligned with my own ideas, } \\
\text { practices, philosophies and stuff like that. } \\
\text { People who I felt like I shared something } \\
\text { with. }\end{array}$ \\
\hline
\end{tabular}




\begin{tabular}{|c|c|c|}
\hline $\begin{array}{l}\text { purposes, to overcome } \\
\text { challenges, or to gain } \\
\text { maximum benefit from a } \\
\text { discussion }\end{array}$ & $\begin{array}{l}\text { - } \begin{array}{l}\text { Statements that describe strategies to } \\
\text { overcome identified constraints to } \\
\text { participation }\end{array} \\
\text { - } \begin{array}{l}\text { Statements that recognize the } \\
\text { relationship among strategies used to } \\
\text { navigate the discussion }\end{array}\end{array}$ & $\begin{array}{l}\text { So, I didn't tend to respond to her, try to } \\
\text { interact with those conversations where she } \\
\text { was at } \\
\text { Sometimes I would go through, when I was } \\
\text { reviewing the discussion posts and I would } \\
\text { see the instructor responded to other } \\
\text { students, so I would kind of look at that } \\
\text { feedback and see what they were saying. } \\
\text { Does this apply to what I've got? Does this } \\
\text { apply to my discussion posts and my work? }\end{array}$ \\
\hline $\begin{array}{l}\text { Assessing Discussion } \\
\text { Participation and } \\
\text { Interaction Strategies } \\
\text { Describing the } \\
\text { effectiveness of specific } \\
\text { discussion or interaction } \\
\text { strategies, }\end{array}$ & $\begin{array}{l}\text { - Statements that consider the } \\
\text { effectiveness of personal or peers } \\
\text { discussion or interaction strategies } \\
\text { including outcomes of participation }\end{array}$ & $\begin{array}{l}\text { Considering I was doing the bare minimum, } \\
\text { I feel like there's a lot of room for } \\
\text { improvement. I think my own improvement } \\
\text { comes from } 2 \text { different sources so one is } \\
\text { internalized thought processes that values } \\
\text { and beliefs and the other is from educational } \\
\text { structure. } \\
\text { and I know her very well, so it was easy to } \\
\text { interact with her. } \\
\text { I feel like there's a lot of room for } \\
\text { improvement. I think my own improvement } \\
\text { comes from } 2 \text { different sources so one is } \\
\text { internalized thought processes that values } \\
\text { and beliefs and the other is from educational } \\
\text { structure. Internally- stop procrastinating } \\
\text { and trying to do more, try to be a better } \\
\text { person. }\end{array}$ \\
\hline
\end{tabular}

